\title{
P212: Antimicrobial resistance and healthcare associated infections: one and only battle
}

\author{
ML Moro*, C Gagliotti, M Marchi, R Buttazzi, V Cappelli, M Morandi, F Morsillo, A Pan, M Parenti, E Ricchizzi \\ From 2nd International Conference on Prevention and Infection Control (ICPIC 2013) \\ Geneva, Switzerland. 25-28 June 2013
}

\section{Introduction}

Integrated surveillance of Healthcare infections (HAIs), antimicrobial resistance (AMR) and antimicrobial consumption $(\mathrm{AC})$ is essential. Its impact in Emilia-Romagna (4.5 million inhabitants) is described.

\section{Methods}

The following surveillance systems exist: electronic-labbased surveillance covering all public and private hospital; AC monitoring system, covering both hospital (HA) and community; alert system of sentinel HAIs and outbreaks, both in HA and long-term care facilities (LTCFs); surgical site infection and intensive care unit surveillance system; repeated prevalence surveys both in HA and LTCFs; regional databases linkage for selected infections (eg Clostridium difficile); ad hoc surveillance for high priority AMR microorganisms (ie carbapenemase-producing Klebsiella pneumoniae-CPK); monitoring of HAIs and antimicrobial stewardship programs in each LHT and of hand hygiene products consumption.

\section{Results}

Selected results are presented below. The incidence rates of bacteremia raised from 146 in 2005 to 228 cases per 100.000 inhabitants/year in $2011(+56 \%)$; the increase was significant for K. pneumoniae (+188\%) and E.coli (+99\%), due to spread of multiresistant strains. An intervention program, launched in July 2011 to fight the spread of CPK, had a positive impact on this trend. The AC significantly increased until 2009; subsequently, the trend is still increasing for hospitals (90.8 DDD/100 in hospital-days in 2011) while in the community the consumption has decreased (following educational campaigns), being still high (18.4 DDD/1.000 inhabitants-day in 2011). In 2007-2011 the coverage of the regional alert system progressively

Area di Programma Rischio Infettivo, Agenzia Sanitaria e Sociale Regione Emilia-Romagna, Bologna, Italy improved: in 200726 HAI outbreaks were notified, and 54 in $2011 ; 17.9 \%$ occurred in LTCFs and $82.1 \%$ in HA. Data on 59,281 non orthopaedic surgeries from 33 categories of surgical procedures have been collected by 41 hospitals (2007-2011): in HAs participating to the surveillance for at least two years, the incidence of surgical wound infections was reduced by $24 \%$ (Odds Ratio $0.76,95 \%$ CI $0.66-0.88$ ).

\section{Conclusion}

An integrated surveillance system, covering both HAIs and AMR, is essential to identify critical areas, to monitor interventions and to demonstrate the success of dedicated efforts.

\section{Disclosure of interest}

None declared.

Published: 20 June 2013

doi:10.1186/2047-2994-2-S1-P212

Cite this article as: Moro et al.: P212: Antimicrobial resistance and healthcare associated infections: one and only battle. Antimicrobial Resistance and Infection Control 2013 2(Suppl 1):P212.

Submit your next manuscript to BioMed Central and take full advantage of:

- Convenient online submission

- Thorough peer review

- No space constraints or color figure charges

- Immediate publication on acceptance

- Inclusion in PubMed, CAS, Scopus and Google Scholar

- Research which is freely available for redistribution

\section{() Biomed Central}

